\title{
Adult neural stem cells:The promise of the future
}

\author{
Philippe Taupin \\ National Neuroscience Institute, \\ National University of Singapore
}

Correspondence: Philippe Taupin

II Jalan Tan Tock Seng, Singapore 308433

Tel +65 63577533

Fax +6562569178

Email obgpit@nus.edu.sg

\begin{abstract}
Stem cells are self-renewing undifferentiated cells that give rise to multiple types of specialized cells of the body. In the adult, stem cells are multipotents and contribute to homeostasis of the tissues and regeneration after injury. Until recently, it was believed that the adult brain was devoid of stem cells, hence unable to make new neurons and regenerate. With the recent evidences that neurogenesis occurs in the adult brain and neural stem cells (NSCs) reside in the adult central nervous system (CNS), the adult brain has the potential to regenerate and may be amenable to repair. The function(s) of NSCs in the adult CNS remains the source of intense research and debates. The promise of the future of adult NSCs is to redefine the functioning and physiopathology of the CNS, as well as to treat a broad range of CNS diseases and injuries.
\end{abstract}

Keywords: neurogenesis, transdifferentiation, plasticity, cellular therapy

\section{Introduction}

Seminal studies in the $60 \mathrm{~s}$ using [3H]-thymidine autoradiographic labeling by Altman and Das were the first to report the generation of new neuronal cells in the adult rodent dentate gyrus (DG), and cell proliferation in the ventricular zone, migration and persisting neurogenesis in the adult olfactory bulb (OB) (Altman and Das 1965; Altman 1969). However, these studies had little impact, because of the paucity of cells labeled and the difficulty of definitively identifying them. It was not until the 1990s, with the advent of new procedures for labeling dividing cells in the CNS, like bromodeoxyuridine (BrdU) (Gratzner 1982; Miller and Nowakowski 1988) and retroviral labelings (Van Praag et al 2002), that neurogenesis in the SVZ and DG really became accepted (Gross 2000; Taupin and Gage 2002). Though over the past decades, significant progresses have been made in the field of adult neurogenesis and NSCs, there is much debate, controversies and questions to be answered.

\section{Adult neurogenesis, facts, and debates Neurogenesis in the adult mammalian brain}

Neurogenesis occurs primarily in two areas of the adult brain in mammals: the DG of the hippocampus and the subventricular zone (SVZ) in several species, including human (Eriksson et al 1998; Curtis et al 2007a). In the DG, newly generated neuronal cells in the subgranular zone (SGZ) migrate to the granular layer, where they differentiate into mature neuronal cells, and extend axonal projections to the CA3 area in rodents and primates. In the SVZ, cells are generated in the anterior part of the SVZ and migrate to the OB, through the rostro-migratory stream (RMS), where they differentiate into interneurons of the $\mathrm{OB}$ in rodent and non-human primates (Taupin and Gage 2002). Newly generated neuronal cells establish functional connections with neighboring cells (Van Praag et al 2002; Carlen et al 2002), particularly GABAergic innervations in the DG, soon after their migration is completed (Wang et al 2005). As many as 9,000 new neuronal cells - or $0.1 \%$ of the granule cell population - are generated per day in the DG of mice, and $65 \%-75 \%$ of the bulbar neurons 
are replaced during a 6 weeks period in young adult rats (Kempermann et al 1997; Kato et al 2001; Cameron and McKay 2001). Among them, a significant proportion undergoes programmed cell death rather than achieving maturity (Morshead and van der Kooy 1992; Cameron and McKay 2001; Gould et al 2001).

The newly generated neuronal cells that survived to maturity may be very stable, and may permanently replace cells born during development, as adult-generated neuronal cells have been reported to survive for extended period of time (eg, for at least 2 years in human DG) (Altman and Das 1965; Eriksson et al 1998; Dayer et al 2003; Kempermann et al 2003). Neurogenesis may also occur, albeit at lower levels, in other areas of the mammalian brain, like the Ammon's horn CA1, neocortex, and substantia nigra (SN) (Gould et al 1999; Rietze et al 2000; Zhao et al 2003). However, some of these reports have been contradicted by other studies (Kornack and Rakic 2001; Lie et al 2002; Frielingsdorf et al 2004; Gould 2007). Hence, the bulk of evidence suggests that there is little if any neurogenesis going on constitutively in other brain regions.

\section{Stem cells in the adult brain}

The origin of newly generated neuronal cells in the adult brain remains the source of controversies. One theory contends that they originate from differentiated ependymal cells in the lateral ventricle, while another contends that they originate from astrocyte-like cells in the SVZ and SGZ (Taupin and Gage 2002). A glial origin for adult generated neuronal cell receives further support recently (Filippov et al 2003; Garcia et al 2004). Hence, the possibility of ependymal origins for NSCs has been has mostly discounted and astrocyte-like cells represent the most accepted model for the source of stem cells of the adult brain.

It is postulated that newly generated neuronal cells originate from residual stem cells in the adult brain. Stem cells are defined by five attributes: proliferation, self-renewal over an extended period of time, generation of a large number of differentiated progeny, maintenance of the homeostasis of the tissue, and regeneration of the tissue following injury (Potten and Loeffler 1990). NSCs are the self-renewing, multipotent cells that generate neurons, astrocytes, and oligodendrocytes of the nervous system. Neural progenitor cells are, as most broadly defined, any cells that do not fulfill all of the attributes of NSCs. Though NSCs remain to be characterized in the adult CNS, self-renewing, multipotent NSC-like cells have been isolated and characterized in vitro from various areas of the adult CNS, neurogenic and non-neurogenic, including the spinal cord, suggesting that NSC may reside throughout the CNS (Taupin and Gage 2002).

There are currently no specific markers of adult NSCs. Nestin, the transcription factors sox-2, oct-3/4, and the RNA-binding protein Musashi 1 are markers for neural progenitor and stem cells, but also label population of glial cells (Lendahl et al 1990; Sakakibara et al 1996; Doetsch et al 1999; Zappone et al 2000; Kaneko et al 2000; Komitova et al 2004; Okuda et al 2004), further fueling the controversies over the origin of newly generated neuronal cells in the adult brain.

\section{Rate and modulation}

The rate of neurogenesis in the rodent DG and SVZ is modulated by various environmental stimuli, physio- and pathological conditions (Taupin 2005). For example, environmental enrichment promotes the survival of newly generated neuronal cells in the DG. Voluntary running stimulates the generation of newly generated neuronal cells in the DG, but not the SVZ. Stress, neuroinflammation and aging decrease neurogenesis in the DG (Nithianantharajah and Hannan 2006; Mora et al 2007). In the diseased brain and after injuries to the CNS, like strokes and traumatic brain injuries (TBIs), neurogenesis is stimulated in the neurogenic areas, and new neuronal cells are generated at the sites of injuries, where they replace some of the degenerated nerve cells (Grote and Hannan 2007). Cell tracking studies revealed that newly generated neuronal cells at sites of injuries originates from the SVZ. Newly generated neuronal cells migrate partially through the RMS to the degenerated areas. It is estimated that $0.2 \%$ of the degenerated nerve cells are replaced in the striatum after focal ischemia (Arvidsson et al 2002). Hence, neurogenesis can be stimulated in the injured brain.

\section{Limit and pitfalls of BrdU labeling}

The modulation of neurogenesis and its quantification have been subject of debates, partly due to the use of BrdU, a thymidine analog, labeling as a method of assessment. As BrdU crosses the blood-brain barrier, it is generally administered intraperiteonally. It is suggested that activity, like exercise, but also the effects of various treatments and physio- and pathological conditions on cerebral flow, metabolism and permeability of the blood-brain barrier to reagents, and in particular to BrdU, may affect the availability of BrdU to the brain. The variation of BrdU quantification observed in these conditions would then reflect the change in BrdU uptake by the cells, rather than the modulation neurogenesis (Taupin 2007). 
With regard to the quantification of neurogenesis with BrdU, one study suggests that the standard concentration used to assess neurogenesis (50-100 $\mathrm{mg} / \mathrm{kg}$ body weight in rodents, intraperitoneal injection) may not label all the dividing cells (Taupin 2007), whereas another study reports that it does (Burns and Kuan 2005). Further systematic studies on BrdU labeling in the CNS are thus needed to further define the conditions in which BrdU can be used for studying neurogenesis. The use of BrdU to study neurogenesis carries other limitations, like labeling of DNA repair, abortive cell cycle reentry and gene duplication, without cell proliferation (Taupin 2007). Other strategies are therefore necessary to make educated conclusions with regard to adult neurogenesis when using BrdU labeling, like the study of markers of the cell cycle and use of retroviruses.

\section{Mechanisms underlying adult neurogenesis}

Most of the mechanisms underlying adult neurogenesis and NSC growth and fate determination are yet to be uncovered. It has been reported that cell death stimulates the proliferation of neural progenitor cells in the adult hippocampus (Gould and Tanapat 1997). Other studies reveal that the mitotic rate is regulated by the number of available progenitor cells, rather than by cell death (Ekdahl et al 2001; Jin et al 2004). On the molecular level, epidermal growth factor and basic fibroblast growth factor were the first mitogens to be identified for neural progenitor and stem cells in vitro, and to stimulate neurogenesis in vivo (Reynolds and Weiss 1992; Gage et al 1995; Craig et al 1996; Kuhn et al 1997). However, other factors present in conditioned medium, like the glycosylated form of the protease inhibitor cystatin $\mathrm{C}(\mathrm{CCg})$, are also required for the proliferation of self-renewing, multipotent NSCs from single cells in vitro (Taupin et al 2000), and remain to be characterized, as well as the pathways of these mitogens and cofactors.

\section{Broader potential of adult stem cells}

Adult stem cells are multipotents; they generate lineage specific cell types restricted to the tissues from which they are derived. Several studies have reported that adult-derived stem cells, and particularly adult-derived neural progenitor and stem cells, may have a broader potential; ie, they generate cell types of lineages other than their tissues of origin (Bjornson et al 1999; Brazelton et al 2000; Mezey et al 2000). However though some studies presented convincing results, phenomenon like contamination, transformation, transdifferentiation, and cell fusion have been reported as possible explanation for the phenotypes observed in some studies (Anderson et al 2001; Mezey 2004).

\section{Function(s) of newborn neuronal cells}

The function(s) of adult neurogenesis has been the source of intense research and debates. Evidences suggest that newly generated neuronal cells participate to process like learning and memory, and depression (Gould et al 1999; Shors et al 2001; Jacobs et al 2000; Santarelli et al 2003). The involvement of adult neurogenesis in learning and memory has been challenged by other studies. Increased hippocampal neurogenesis has been observed without improvement of learning and memory performances, in the Morris water maze test, in mice selectively bred for high levels of wheel running (Rhodes et al 2003). Therefore the function of newly generated neuronal cells in the adult brain remains to be determined.

Finally, the evidence that neurogenesis occurs in the adult brain, and that NSCs reside in the adult CNS provide new avenues for cellular therapy. Cell therapeutic intervention may involve the stimulation of endogenous or the transplantation of neural progenitor and stem cells of the adult CNS. However, adult NSCs have yet to be brought to therapy.

Though it is now accepted that neurogenesis occurs in the adult brain and NSCs reside in the adult CNS, much questions and controversies remain to be answered: what is the origin of newly generated neuronal cells in the adult brain, what are their molecular markers, what are the factors and mechanisms controlling NSC growth and fate specification, what is the potential of adult-derived stem cells, what are the functions of newly generated neuronal cells in the adult brain, and how can we use adult NSCs therapeutically?

\section{The future of adult neurogenesis}

Newly generated neuronal cells represent a small fraction of nerve cells in the adult brain. But data presented above suggest that their relevance to CNS physio- and pathology, and cellular therapy as significant, but yet to be uncovered. One of the key underlyings of the importance of newly generated neuronal cells is their relative contributions compare to the preexisting network to CNS functioning. One can postulate that such contribution will depend on the specific properties of adult generated neuronal cells.

\section{On the functioning of newly generated neuronal cells in the adult brain}

Adult newly generated neuronal cells belong to three groups based on their destinies. The first group consists of the newly 
generated neuronal cells that will undergo post-mitotic death (Morshead and van der Kooy 1992; Cameron and McKay 2001). The second group represents a population of newly generated cells that neither undergo apoptosis, nor differentiate to a defined fate. This latter group of cells likely contributes to renewing the stem cell niche. Niches are specialized microenvironments that regulate stem cells activity (Moore and Lemischka 2006; Scadden 2006). In the adult brain, neurogenic niches are maintained in restricted regions and have been identified and characterized (Alvarez-Buylla and Lim 2004). These niches, an angiogenic and an astroglial niches, control NSCs self-renewal and differentiation (Palmer et al 2000; Song et al 2002). It is hypothesized that neurogenic niches underlie the properties and functions of NSCs in the adult CNS (Alvarez-Buylla and Lim 2004; Taupin 2006; Lim et al 2007). The third group consists of the newly generated neuronal cells that will survive to maturity and integrate the network (Altman and Das 1965; Eriksson et al 1998; Kempermann et al 2003; Dayer et al 2003).

Several lines of evidence suggest that newly generated neuronal cells have different properties and physiological functions, than mature nerve cells, that may underlie their specific functions. Young granule cells in the adult DG appear to exhibit robust long-term potentiation that, in contrast to mature granule cells, cannot be inhibited by GABA (Wang et al 2000). More recently, newly generated neuronal cells in the adult hippocampus were characterized as receiving GABAergic excitatory input (Ge et al 2005, 2007; Tozuka et al 2005), a function of GABA previously reported during development (Ben-Ari 2002). Once cells have matured and integrated the pre-existing network, they may then functionally replace nerve cells born during development. Among the questions that arise from such theory are: What are the physiological functions of the newly generated neural cells during the time they are distinct from their mature counterpart? What is the function of such cellular renewal? Why would it occur only and specifically in discrete areas of the adult brain?

\section{On the functionality of newly generated neuronal cells in the adult brain}

The increase of neurogenesis in diseases, disorders, and after injuries might then serve a neuroadaptative process (Figure 1). Patients with neurological diseases, like Alzheimer's disease, epilepsy, and Parkinson's disease (PD), but also recovering from strokes and injuries, are at greater risk of depression (Perna et al 2003; Gilliam et al 2004; Sawabini and Watts
2004) and present memory impairments (Kotloski et al 2002; Wang et al 2004). Since learning and memory, and depression are associated with hippocampal neurogenesis (Gould et al 1999; Jacobs et al 2000; Shors et al 2001; Santarelli et al 2003), the depressive episode and learning impairments in patients suffering from neurological diseases, or disorders may contribute to the regulation of neurogenesis, in an additive, or cooperative manner with the disorder. Therefore, modulation of neurogenesis in the hippocampus might be an attempt by the CNS to compensate for other neuronal functions associated with the disease, like depression, and learning and memory impairments.

The increase in neurogenesis would also be a factor contributing to the plasticity of the CNS, and particularly related to the recovery in the CNS after injury. After cerebral strokes and TBIs, there is a striking amount of neurological recovery in the following months and years, despite often-permanent structural damage (Sbordone et al 1995; Anderson et al 2000). Though the mechanisms underlying such recovery are not fully understood, properties of plasticity of the CNS, like the reorganization of the preexisting network and axonal sprouting have been implicated in the recovery (Ramic et al 2006; Kolb and Gibb 2007). Particularly, reorganization of the contra-lateral hemisphere has been involved in plasticity after brain injury (Cramer and Basting 2000). Neurogenesis is increased bilaterally in the DG and the SVZ after cerebral strokes and TBIs. The bilateral increase in neurogenesis would contribute to the plasticity related recovery in the CNS, and particularly after injury.

The generation of newly generated neuronal cells at the sites of injury could represent a regenerative attempt by the CNS. In the diseased brain and after injuries to the CNS, new neuronal cells are generated at the sites of degeneration, where they replace some of the lost nerves cells (Arvidsson et al 2002). Hence, there is no functional recovery. The generation of new neuronal cells at the sites of injury could represent an attempt by the CNS to regenerate following injury. Several hypotheses can explain the lack of recovery of the CNS after injury. The number of new neurons generated may be too low to compensate for the neuronal loss: $0.2 \%$ of the degenerated nerve cells in the striatum after focal ischemia (Arvidsson et al 2002). The neuronal cells that are produced are nonfunctional because they do not develop into fully mature neurons, because they do not develop into the right type of neurons, or because they are incapable of integrating into the surviving brain circuitry. Gliogenesis has also been reported to occur at the sites of injuries (Fawcett 


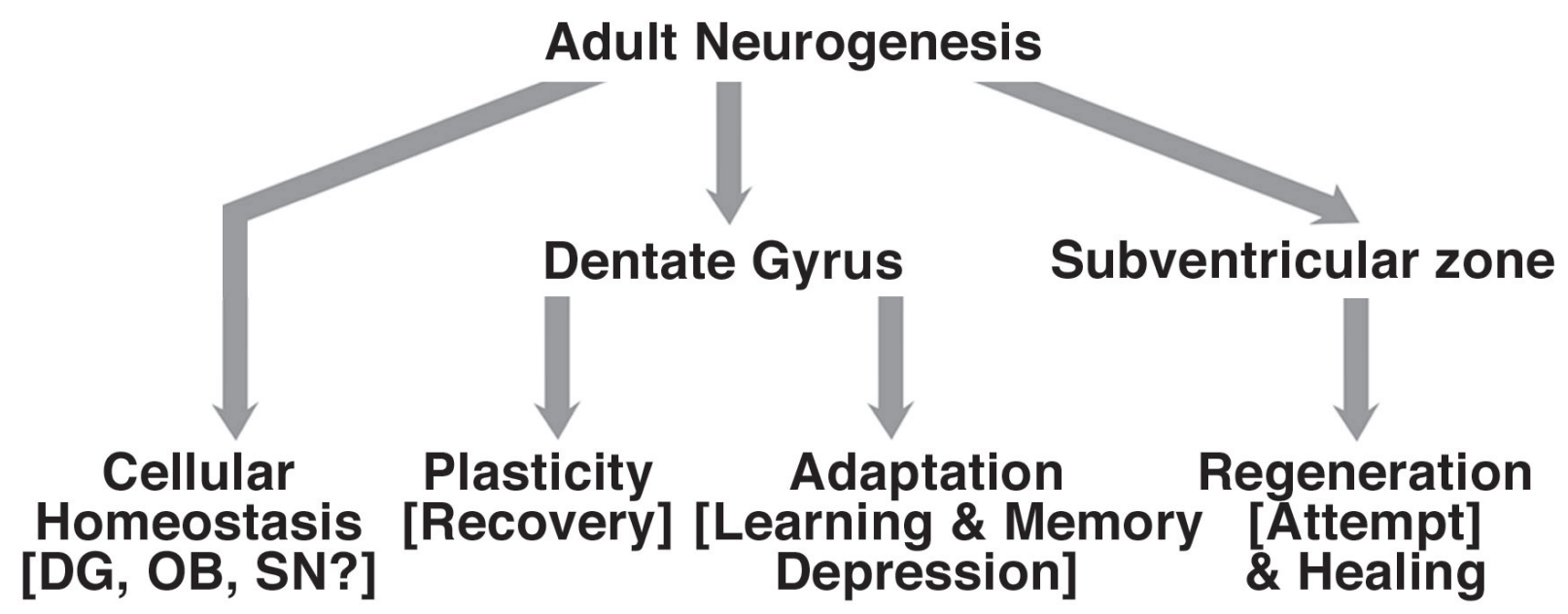

Figure I Functionality of adult neurogenesis. Adult neurogenesis occurs throughout adulthood. Hence the physiological function(s) of adult neurogenesis remains to be elucidated. Adult neurogenesis may be involved in the physiopathology of CNS functioning.

- Patients with neurological diseases, like Alzheimer's disease, epilepsy, and Parkinson's disease, but also recovering from stroke and injury, are at greater risk of depression and present memory impairment. Since learning and memory, depression are associated with hippocampal neurogenesis, the increase of neurogenesis in diseases, disorders, and after injuries might then serve a neuroadaptative process.

- After cerebral strokes and traumatic brain injuries, there is a striking amount of neurological recovery in the following months and years, despite often-permanent structural damage. The increase in neurogenesis would also be a factor contributing to the plasticity of the CNS, and particularly related to the recovery in the CNS after injury.

- In the diseased brain and after injuries to the CNS, new neuronal cells are generated at the sites of degeneration, where they replace some of the lost nerves cells. The generation of newly generated neuronal cells at the sites of injury could represent a regenerative attempt by the CNS, and its participation to the healing process.

- The total number of neurons in the adult brain does not dramatically increase, and cell death is an established process in that adult brain. Newly generated neuronal cells may contribute to cellular homeostasis. The desequilibrium in cellular homeostasis may result in neurodegenerative diseases.

The relative contribution of adult neurogenesis to these processes remains to be elucidated. Specific properties of newly generated neuronal cells yet to be determined would underlie the role of newly generated neuronal cells in CNS functioning.

and Asher 1999). Therefore, neurogenesis and gliogenesis at the site of injuries may participate to a healing process.

The total number of neurons in the adult brain does not dramatically increase, and cell death is an established process in that adult brain (Gould et al 2001). Newly generated neuronal cells may contribute to homeostasis of the tissue. Neurogenic niches have been described in the adult brain, and may hold the molecular and cellular cues to such phenomenon (Alvarez-Buylla and Lim 2004). On the physiopathological level, an explanation is yet to be brought. It is worth mentioning that it has been suggested that since environmental enrichment promotes adult neurogenesis, and standard laboratory living condition do not represent physiological environment, neurogenesis may occur more broadly, at low level, that would remain undetected (Taupin 2007), though such eventuality remains to be proven in mammals. Indeed, it has been proposed that self-repair mechanisms may operate in the adult rodent SN (Zhao et al 2003), the area of the CNS affected in PD. If such turn-over of dopaminergic neuronal cells was confirmed, progression of the disease would then be determined not only by the rate of degeneration of SN neurons, but also by the efficacy in the formation of new dopamine neurons. Thus, disturbances of the equilibrium of cellular homeostasis could result in neurodegenerative diseases. So, in PD, neurogenesis might not only be a process for functional recovery, but it may also play a key role in the pathology of the disease. However, these data remain the source of controversies (Lie et al 2002; Frielingsdorf et al 2004), and such hypothesis remains to be demonstrated.

Though at this time these hypotheses remain mostly speculative, the future of adult neurogenesis and NSC research lies in our understanding of the specific role and relative contribution of newly generated neuronal cells to the physio- and pathology of the CNS.

\section{The promise of adult neural stem cells}

The promise of adult NSCs lie also in our ability to bring adult NSC research to therapy. Because of their potential to generate the main phenotype of the CNS, NSCs hold the promise to cure a broad range of CNS diseases and injuries. The confirmation that neurogenesis occurs in the adult brain and NSCs reside in the adult CNS, opens new avenues for cellular therapy. Cell therapeutic intervention may involve the stimulation or grafting of neural progenitor and stem cells (Okano et al 2007; Yamashima et al 2007). The generation of new neuronal cells at the sites of injury further highlights 
Table I Adult neurogenesis and neural stem cells. Key publications

\begin{tabular}{ll}
\hline Year & Event (references) \\
\hline 1965 & Seminal studies on adult neurogenesis (Altman and Das I965) \\
1982 & Monoclonal antibody against BrdU (Gratzner 1982) \\
1988 & BrdU a marker to study neurogenesis (Miller and Nowakowski 1988) \\
1990 & Identification of nestin as a marker for neural progenitor and stem cells (Lendahl et al I990) \\
1992 & Post-mitotic cell death of newly generated neuronal cells in adult SVZ (Morshead and van der Kooy I992) \\
1992 & Isolation and characterization of neural progenitor and stem cells from the adult rodent SVZ (Reynolds and Weiss \\
& I992) \\
1995 & Isolation and characterization of neural progenitor and stem cells from the adult rodent hippocampus, adult hip \\
1997 & pocampal-derived neural progenitor, and stem cells grafted in adult brain (Gage et al 1995) \\
1998 & Environmental enrichment promotes adult neurogenesis (Kempermann et al I997) \\
1999 & Characterization of adult neurogenesis in the adult human hippocampus (Eriksson et al I998) \\
1999 & Broader potential of adult-derived neural progenitor and stem cells (Bjornson et al 1999) \\
2001 & Glial origin for newly generated neural stem cells in the SVZ (Doetsch et al I999) \\
$200 I$ & Post-mitotic cell death of newly generated neuronal cells in adult hippocampus (Cameron and McKay 200I) \\
& Isolation and characterization of neural progenitor and stem cells from human post-mortem tissues and biopsies \\
2005 & (Palmer et al 200I) \\
2007 & Newly generated neuronal cells receive GABAergic excitatory input (Tozuka et al 2005) \\
\hline
\end{tabular}

the potential of the CNS to repair itself. The SVZ origin of the newly generated neuronal cells suggests that the stimulation of neurogenesis in the SVZ would provide a strategy to promote functional recovery after injury (Curtis et al 2007b). Alternatively, the potential to isolate neural progenitor and stem cells from nondegenerated brain areas from the patient himself would provide an autologous source of transplantable neural progenitor and stem cells, thereby obviating the need to find a matching donor for the tissues and the use of drugs that suppress the immune system; thereby increasing the chance of successful graft and recovery. However such strategy would involve invasive surgery and the destruction of healthy brain tissue, a limiting factor for its clinical application. Neural progenitor and stem cells have also been isolated from human post-mortem tissues, providing an alternative source of tissues for cellular therapy (Palmer et al 2001).

\section{Conclusion}

The promise of the future of adult neurogenesis and NSC research lies in our understanding of the function and relative contribution of newly generated neuronal cells in the adult brain, and our ability to bring adult NSC to therapy. The molecular, cellular, and physiological characterization of adult NSCs is a prerequisite to such endeavor. Significant advances have already been made in just the past decades. Because of the potential of adult neurogenesis and NSCs to redefine brain functioning, physio- and pathology, and its potential to cure a broad range of CNS diseases and injuries, the future of this field of research is tantalizing.

\section{Acknowledgments}

P.T. is supported by grants from the NMRC, BMRC, and the Juvenile Diabetes Research Foundation.

\section{References}

Altman J. 1969. Autoradiographic and histological studies of postnatal neurogenesis. IV. Cell proliferation and migration in the anterior forebrain, with special reference to persisting neurogenesis in the olfactory bulb. J Comp Neurol, 137:433-58.

Altman J, Das GD. 1965. Autoradiographic and histological evidence of postnatal hippocampal neurogenesis in rats. J Comp Neurol, 124:319-6.

Alvarez-Buylla A, Lim DA. 2004. For the long run, maintaining germinal niches in the adult brain. Neuron, 41:683-6.

Anderson DJ, Gage FH, Weissman IL. 2001. Can stem cells cross lineage boundaries? Nat Med, 7:393-5.

Anderson V, Catroppa C, Morse S, et al. 2000. Recovery of intellectual ability following traumatic brain injury in childhood: impact of injury severity and age at injury. Pediatr Neurosurg, 32:282-90.

Arvidsson A, Collin T, Kirik D, et al. 2002. Neuronal replacement from endogenous precursors in the adult brain after stroke. Nat Med, 8:963-70.

Ben-Ari, Y. 2002. Excitatory actions of gaba during development: the nature of the nurture. Nat Rev Neurosci, 3:728-39.

Brazelton TR, Rossi FM, Keshet GI, et al. 2000. From marrow to brain: expression of neuronal phenotypes in adult mice. Science, 290:1775-9.

Bjornson CR, Rietze RL, Reynolds BA, et al. 1999. Turning brain into blood: a hematopoietic fate adopted by adult neural stem cells in vivo. Science, 283:534-7.

Burns KA, Kuan CY. 2005. Low doses of bromo- and iododeoxyuridine produce near-saturation labeling of adult proliferative populations in the dentate gyrus. Eur J Neurosci, 21:803-7.

Cameron HA, McKay RD. 2001. Adult neurogenesis produces a large pool of new granule cells in the dentate gyrus. J Comp Neurol, 435:406-17. 
Carlen M, Cassidy RM, Brismar H, et al. 2002. Functional integration of adult-born neurons. Curr Biol, 12:606-8.

Cramer SC, Bastings EP. 2000. Mapping clinically relevant plasticity after stroke. Neuropharmacology, 39:842-51.

Craig CG, Tropepe V, Morshead CM, et al. 1996. In vivo growth factor expansion of endogenous subependymal neural precursor cell populations in the adult mouse brain. $J$ Neurosci, 16:2649-58.

Curtis MA, Kam M, Nannmark U, et al. 2007a. Human neuroblasts migrate to the olfactory bulb via a lateral ventricular extension. Science, 315:1243-9.

Curtis MA, Eriksson PS, Faull RL. 2007b. Progenitor cells and adult neurogenesis in neurodegenerative diseases and injuries of the basal ganglia. Clin Exp Pharmacol Physiol, 34:528-32.

Dayer AG, Ford AA, Cleaver KM, et al. 2003. Short-term and long-term survival of new neurons in the rat dentate gyrus. J Comp Neurol, 460:563-72.

Doetsch F, Caille I, Lim DA, et al. 1999. Subventricular zone astrocytes are neural stem cells in the adult mammalian brain. Cell, 97:703-16.

Ekdahl CT, Mohapel P, Elmer E, et al. 2001. Caspase inhibitors increase short-term survival of progenitor-cell progeny in the adult rat dentate gyrus following status epilepticus. Eur J Neurosci, 14:937-45.

Eriksson PS, Perfilieva E, Bjork-Eriksson T, et al. 1998. Neurogenesis in the adult human hippocampus. Nat Med, 4:1313-7.

Fawcett JW, Asher RA. 1999. The glial scar and central nervous system repair. Brain Res Bull. 49:377-91.

Filippov V, Kronenberg G, Pivneva T, et al. 2003. Subpopulation of nestinexpressing progenitor cells in the adult murine hippocampus shows electrophysiological and morphological characteristics of astrocytes. Mol Cell Neurosci, 23:373-82.

Frielingsdorf H, Schwarz K, Brundin P, et al. 2004. No evidence for new dopaminergic neurons in the adult mammalian substantia nigra. Proc Natl Acad Sci U S A, 101:10177-82.

Gage FH, Coates PW, Palmer TD, et al. 1995. Survival and differentiation of adult neuronal progenitor cells transplanted to the adult brain. Proc Natl Acad Sci USA, 92:11879-83.

Garcia AD, Doan NB, Imura T, et al. 2004. GFAP-expressing progenitors are the principal source of constitutive neurogenesis in adult mouse forebrain. Nat Neurosci, 7:1233-41.

Ge S, Goh EL, Sailor KA, et al. 2005. GABA regulates synaptic integration of newly generated neurons in the adult brain. Nature, 439:589-93.

Ge S, Pradhan DA, Ming GL, et al. 2007. GABA sets the tempo for activity-dependent adult neurogenesis. Trends Neurosci, 30:1-8.

Gilliam FG, Santos J, Vahle V, et al. 2004. Depression in epilepsy: ignoring clinical expression of neuronal network dysfunction? Epilepsia, 45:28-33.

Gould E. 2007. How widespread is adult neurogenesis in mammals? Nat Rev Neurosci, 8:481-8.

Gould E, Tanapat P. 1997. Lesion-induced proliferation of neuronal progenitors in the dentate gyrus of the adult rat. Neurosci, 80:427-36.

Gould E, Beylin A, Tanapat P, et al. 1999. Learning enhances adult neurogenesis in the hippocampal formation. Nat Neurosci, 2:260-5.

Gould E, Reeves AJ, Graziano MS, et al. 1999. Neurogenesis in the neocortex of adult primates. Science, 286:548-52.

Gould E, Vail N, Wagers M, et al. 2001. Adult-generated hippocampal and neocortical neurons in macaques have a transient existence. Proc Natl Acad Sci USA, 98:10910-7.

Gross CG. 2000. Neurogenesis in the adult brain: death of a dogma. Nat Rev Neurosci, 1:67-73.

Gratzner HG. 1982. Monoclonal antibody to 5-bromo- and 5-iododeoxyuridine: A new reagent for detection of DNA replication. Science, 218:474-5.

Grote HE, Hannan AJ. 2007. Regulators of adult neurogenesis in the healthy and diseased brain. Clin Exp Pharmacol Physiol, 34:533-45.

Jacobs BL, Praag H, Gage FH. 2000. Adult brain neurogenesis and psychiatry: a novel theory of depression. Mol Psychiatry, 5:262-9.

Jin K, Galvan V, Xie L, et al. 2004. Enhanced neurogenesis in Alzheimer's disease transgenic (PDGF-APPSw,Ind) mice. Proc Natl Acad Sci USA, 101:13363-7.

Kaneko Y, Sakakibara S, Imai T, et al. 2000. Musashi1: an evolutionally conserved marker for CNS progenitor cells including neural stem cells. Dev Neurosci, 22:139-53.
Kato T, Yokouchi K, Fukushima N. 2001. Continual replacement of newlygenerated olfactory neurons in adult rats. Neurosci Lett, 307:17-20.

Kempermann G, Kuhn HG, Gage FH. 1997. More hippocampal neurons in adult mice living in an enriched environment. Nature, 386:493-5.

Kempermann G, Gast D, Kronenberg G, et al. 2003. Early determination and long-term persistence of adult-generated new neurons in the hippocampus of mice. Development, 130:391-9.

Kolb B, Gibb R. 2007. Brain plasticity and recovery from early cortical injury. Dev Psychobiol, 49:107-18.

Komitova M, Eriksson PS. 2004. Sox-2 is expressed by neural progenitors and astroglia in the adult rat brain. Neurosci Lett, 369: 24-7.

Kornack DR, Rakic P. 2001. Cell proliferation without neurogenesis in adult primate neocortex. Science, 294:2127-30.

Kotloski R, Lynch M, Lauersdorf S, Sutula T. 2002. Repeated brief seizures induce progressive hippocampal neuron loss and memory deficits. Prog Brain Res, 135:95-110.

Kuhn HG, Winkler J, Kempermann G, et al. 1997. Epidermal growth factor and fibroblast growth factor-2 have different effects on neural progenitors in the adult rat brain. $J$ Neurosci, 17:5820-9.

Lendahl U, Zimmerman LB, McKay RD. 1990. CNS stem cells express a new class of intermediate filament protein. Cell, 60:585-95.

Lie DC, Dziewczapolski G, Willhoite AR, et al. 2002. The adult substantia nigra contains progenitor cells with neurogenic potential. J Neurosci, 22:6639-49.

Lim DA, Huang YC, Alvarez-Buylla A. 2007. The adult neural stem cell niche: lessons for future neural cell replacement strategies. Neurosurg Clin N Am, 18:81-92, ix.

Mezey E, Chandross KJ, Harta G, et al. 2000. Turning blood into brain: cells bearing neuronal antigens generated in vivo from bone marrow. Science, 290:1779-82.

Mezey E. 2004. Commentary: on bone marrow stem cells and openmindedness. Stem Cells Dev, 13:147-52.

Miller MW, Nowakowski RS. 1988. Use of bromodeoxyuridine-immunohistochemistry to examine the proliferation, migration and time of origin of cells in the central nervous system. Brain Res, 457:44-52.

Moore KA, Lemischka IR. 2006. Stem cells and their niches. Science, 311:1880-5.

Mora F, Segovia G, Del Arco A. 2007. Aging, plasticity and environmental enrichment: Structural changes and neurotransmitter dynamics in several areas of the brain. Brain Res Rev, 55:78-88.

Morshead CM, van der Kooy D. 1992. Postmitotic death is the fate of constitutively proliferating cells in the subependymal layer of the adult mouse brain. J Neurosci, 12:249-56.

Nithianantharajah J, Hannan AJ. 2006. Enriched environments, experiencedependent plasticity and disorders of the nervous system. Nat Rev Neurosci, 7:697-709.

Okano H, Sakaguchi M, Ohki K, et al. 2007. Regeneration of the central nervous system using endogenous repair mechanisms. $J$ Neurochem, 102:1459-65.

Okuda T, Tagawa K, Qi ML, et al. 2004. Oct-3/4 repression accelerates differentiation of neural progenitor cells in vitro and in vivo. Brain Res Mol. Brain Res. 132:18-30.

Palmer TD, Willhoite AR, Gage FH. 2000. Vascular niche for adult hippocampal neurogenesis. J Comp Neurol, 425:479-94.

Palmer TD, Schwartz PH, Taupin P, et al. 2001. Cell culture. Progenitor cells from human brain after death. Nature, 411:42-3.

Perna RB, Rouselle A, Brennan P. 2003. Traumatic brain injury: depression, neurogenesis, and medication management. $J$ Head Trauma Rehabil, 18:201-3.

Potten CS, Loeffler M. 1990. Stem cells: attributes, cycles, spirals, pitfalls and uncertainties. Lessons for and from the crypt. Development, 110:1001-20.

Ramic M, Emerick AJ, Bollnow MR, et al. 2006. Axonal plasticity is associated with motor recovery following amphetamine treatment combined with rehabilitation after brain injury in the adult rat. Brain Res, 1111:176-86.

Reynolds BA, Weiss S. 1992. Generation of neurons and astrocytes from isolated cells of the adult mammalian central nervous system. Science, 255:1707-10. 
Rhodes JS, van Praag H, Jeffrey S, et al. 2003. Exercise increases hippocampal neurogenesis to high levels but does not improve spatial learning in mice bred for increased voluntary wheel running. Behav Neurosci, 117:1006-16. Erratum in: 2003. Behav Neurosci, 118:305.

Rietze R, Poulin P, Weiss S. 2000. Mitotically active cells that generate neurons and astrocytes are present in multiple regions of the adult mouse hippocampus. J Comp Neurol, 424:397-408.

Sakakibara S, Imai T, Hamaguchi K, et al. 1996. Mouse-Musashi-1, a neural RNA-binding protein highly enriched in the mammalian CNS stem cell. Dev Biol, 176:230-42.

Santarelli L, Saxe M, Gross C, et al. 2003. Requirement of hippocampal neurogenesis for the behavioral effects of antidepressants. Science, 301:805-9.

Sawabini KA, Watts RL. 2004. Treatment of depression in Parkinson's disease. Parkinsonism Relat Disord, 10:S37-41.

Sbordone RJ, Liter JC, Pettler-Jennings P. 1995. Recovery of function following severe traumatic brain injury: a retrospective 10-year follow-up. Brain Inj, 9:285-99.

Scadden DT. 2006. The stem-cell niche as an entity of action. Nature, 441:1075-9.

Shors TJ, Miesegaes G, Beylin A, et al. 2001. Neurogenesis in the adult is involved in the formation of trace memories. Nature, 410:372-6. Erratum in: 2001. Nature, 414:938.

Song H, Stevens CF, Gage FH. 2002. Astroglia induce neurogenesis from adult neural stem cells. Nature, 417:39-44.

Taupin P, Ray J, Fischer WH, et al. 2000. FGF-2-responsive neural stem cell proliferation requires $\mathrm{CCg}$, a novel autocrine/paracrine cofactor. Neuron, 28:385-97.

Taupin P, Gage FH. 2002. Adult neurogenesis and neural stem cells of the central nervous system in mammals. J Neurosci Res, 69:745-9.
Taupin P. 2005. Adult neurogenesis in the mammalian central nervous system: functionality and potential clinical interest. Med Sci Monit, 11:RA247-52.

Taupin P. 2007. BrdU Immunohistochemistry for Studying Adult Neurogenesis: paradigms, pitfalls, limitations, and validation. Brain Res Rev, 53:198-214.

Taupin P. 2006. Adult neural stem cells, neurogenic niches and cellular therapy. Stem Cell Reviews, 2:213-20.

Tozuka Y, Fukuda S, Namba T. 2005. GABAergic excitation promotes neuronal differentiation in adult hippocampal progenitor cells. Neuron, 47:803-15.

Van Praag H, Schinder AF, Christie BR, et al. 2002. Functional neurogenesis in the adult hippocampus. Nature, 415:1030-4.

Wang LP, Kempermann G, Kettenmann H. 2005. Subpopulation of precursor cells in the mouse dentate gyrus receives synaptic GABAergic input. Mol Cell Neurosci, 29:181-9.

Wang R, Dineley KT, Sweatt JD, et al. 2004. Presenilin 1 familial Alzheimer's disease mutation leads to defective associative learning and impaired adult neurogenesis. Neurosci, 126:305-12.

Wang S, Scott BW, Wojtowicz JM. 2000. Heterogenous properties of dentate granule neurons in the adult rat. $J$ Neurobiol, 42:248-57.

Yamashima T, Tonchev AB, Yukie M. 2007. Adult hippocampal neurogenesis in rodents and primates: endogenous, enhanced, and engrafted. Rev Neurosci, 18:67-82.

Zappone MV, Galli R, Catena R, et al. 2000. Sox2 regulatory sequences direct expression of a (beta)-geo transgene to telencephalic neural stem cells and precursors of the mouse embryo, revealing regionalization of gene expression in CNS stem cells. Development, 127:2367-82.

Zhao M, Momma S, Delfani K, et al. 2003. Evidence for neurogenesis in the adult mammalian substantia nigra. Proc Natl Acad Sci USA, 100: 7925-30. 